\title{
SURGIMIENTO DE LAS CIENCIAS COGNITIVAS: CONTEXTO Y ARQUITECTURA IDEOLÓGICA
}

\author{
Sergio Dansilio
}

\author{
Reseña a cargo de la \\ Prof. G. 5 Dra. Lilian R. Daset \\ Facultad de Psicología. \\ Universidad Católica del Uruguay
}

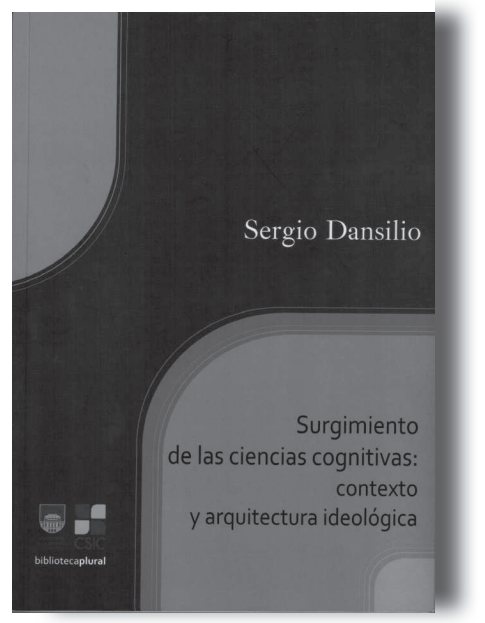

El autor entrega este trabajo como producto de lo que, en los inicios, fuera su Tesis de Maestría en Ciencias Humanas en la opción Filosofía y Sociedad (Facultad de Humanidades y Ciencias de la Educación, UDELAR) y desde ahí es que nos acerca a ese diálogo -me permito decir que interno primero- entre el neurólogo y el epistemólogo, rara y rica conjunción de conocimientos en una misma persona, lo que hace ciertamente compleja la tarea de escribir algunas notas referidas a este libro en particular.

La publicación nos invita a un viaje por algunos de los momentos relevantes en el surgimiento de las Ciencias Cognitivas -en un escenario post $2 \mathrm{da}$. guerra mundial- y a través de autores que en los años 80 examinan ese advenimiento; donde la metáfora de la mente como computadora - y su incorporación para muchos con un carácter de naturaleza- y algunas de las implicaciones que esto trajo para la Psicología, son un apreciable detonador para la discusión académica, ya desde la lectura más epistemológica que hace el autor, ya desde un encare más desde la psicología cognitiva aplicada.

Para el autor, las ciencias cognitivas posibilitan el despliegue de una nueva ontología, tema sobre el que discurre en su tercer apartado -que no capítulo-, con una red de explicaciones venidas de la física, las matemáticas, la biología y la informática y siempre con el sujeto como protagonista, neurológica, social, política y científicamente pensante, donde nos rememora, actualizada, la discusión sobre la libertad y el determinismo. El escenario se va dibujando desde la dualidad inicial entre inteligencia artificial e inteligencia protoplasmática, hasta la simulación jugando ¿o siendo? realidad y la incorporación del mundo cyborg a nuestra cotidianeidad y nuevamente, el lugar del sujeto en ese escenario.

A lo largo del libro, se van bosquejando aspectos de esa arquitectura ideológica de las ciencias cognitivas a que hace referencia el título, con una mirada que recoge los trabajos sustentados en una concepción donde los procesos mentales son asimilados a procesos computacionales y el análisis así discurre sobre una de las "posibles derivaciones 
ideológicas"(Dansilio, 2012, pag.75). En los apartados finales se explicitan una serie de constructos básicos sobre la ciencia y la ideología y también se abren puertas a la discusión fundada, atendiendo a que indudablemente tras cada propuesta teórica hay alguna ideología imperante pero es una valla que puede ser salvada; se acentúa el desafío que implica para el lector recoger alguna de las cuestiones que este trabajo permite vislumbrar.

En Psicología algunas de las discusiones que propone Dansilio no han alcanzado su punto máximo de debate; especialmente pensando en los productos que van surgiendo de la Psicología Cognitiva aplicada, donde no se ha generado aún la masa crítica de productos discursivos, pero por otro lado, se avanza hacia nuevas y cada vez menos minimalistas metáforas - ¿naturalezas?-. Este trabajo azuza e invita a esa necesaria reflexión y debate, por las fases que siguieron a esta etapa fundacional y además, por las síntesis que la historia misma va propiciando.

Dansilio, S. (2012). Surgimiento de las ciencias cognitivas: contexto y arquitectura ideológica. CSIC. Universidad de la República, Uruguay. 